\title{
Aminolysis of 4-Nitrobenzenesulfenyl Chloride
}

\author{
Jong Pal Lee, ${ }^{*}$ Sung Sik Lee, ${ }^{\dagger}$ and In Sun Koo, ${ }^{\ddagger}$ \\ Department of Chemistry, Dong-A University, Busan 604-714, Korea. *E-mail: jplee@dau.ac.kr \\ † Department of Chemical Engneering, Dong-A University, Busan 604-714, Korea \\ ${ }^{\star}$ Department of Chemistry Education and Research Institute of Natural Science, \\ Gyeongsang National University, Jinju 600-701, Korea. *E-mail: iskoo@gsnu.ac.kr \\ Received December 3, 2010, Accepted January 8, 2011
}

Key Words : 4-Nirobenznenesulfenyl chloride, Stepwise mechanism, Hypervalent intermediate

Nucleophilic substitution reactions at a dicoordinated sulfur compound take place through a bimolecular mechanism ${ }^{1,2}$ as well as a tricoordinated sulfur compound..$^{3-5}$ These reactions are well known to proceed through a stepwise mechanism with a hypervalent sulfur species(sulfuranide) as an intermediate or through a single step with synchronous bond formation and breaking ( $\mathrm{S}_{N} 2$ type mechanism) as shown in Scheme 1 .

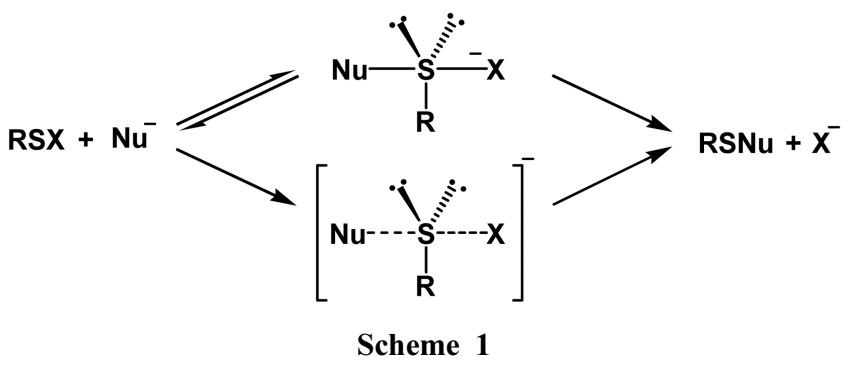

The tool of criterion for the mechanism of nucleophilic substitution reactions has been most frequently used Bronsted and Hammett eq. For example, a break or curvature in Bronsted plot has often been observed for the aminolysis of ester with good leaving group. ${ }^{6,7}$ Nonlinear free energy relationships have been often interperated as a change of a rate determining step for a stepwise mechanism, while a linear Bronsted plot suggests no change in mechanism.

The studies on nucleophilic substitution reactions of a dicoordinated sulfur compound are very rare in comparison with those of a tricoordinated or tetracoordinated sulfur compounds. The authors have performed the kinetic studies

Table 1. Observed First-Order Rate Constants $\left(k_{\mathrm{obsd}}\right)$ for the Reaction of 4-Nitrobenzenesulfenyl Chloride with X-Benzylamines in DMSO at $25^{\circ} \mathrm{C}$

\begin{tabular}{ccc}
\hline $\mathrm{X}$ & {$[\mathrm{X}-\mathrm{BnA}] / 10^{-2} \mathrm{M}$} & $k_{\mathrm{obsd}} / 10^{-4} \mathrm{~s}^{-1}$ \\
\hline $4-\mathrm{OCH}_{3}$ & $3.88-27.3$ & $3.03-59.6$ \\
$4-\mathrm{CH}_{3}$ & $3.88-27.3$ & $2.46-28.0$ \\
& & $(1.55-16.6)^{a}$ \\
$\mathrm{H}$ & $3.88-27.3$ & $2.10-15.2$ \\
$4-\mathrm{Cl}$ & $3.88-27.3$ & $1.93-7.50$ \\
& & $(0.961-2.31)^{a}$ \\
\hline
\end{tabular}

${ }^{a}$ For deuterated X-benzylamine $\left(\mathrm{XC}_{6} \mathrm{H}_{4} \mathrm{CH}_{2} \mathrm{ND}_{2}\right)$. on the reaction of 4-nitrobenzenesulfenyl chloride with substituted (X)benzylamines in DMSO at $25^{\circ} \mathrm{C}$ to gain further information into the aminolysis mechanism of a dicoordinated sulfur compound.

\section{Results and Discussion}

The reaction of 4-nitrobenzenesulfenyl chloride with benzylamines in DMSO obeyed pseudo-first order kinetics under large excess amine concentration. Pseudo-first-order rate constant $\left(k_{\text {obsd }}\right)$ was obtained from the slope of the plot of $\ln \left(\lambda-\lambda_{t}\right) v s$ time and listed in Table 1 .

The $k_{\text {obsd }}$ value increases with increasing concentration of amine, but it shows the upward curvature at higher concentration of amine as shown in Figure 1. Therefore, the $k_{\text {obsd }}$ can be given by Eq. (1), where $k_{\mathrm{o}}$ is the solvolytic rate constant, and $k_{2}, k_{3}$ are the second order and the third order rate constants with X-benzylamine, respectively. When the reactions take place as described in Eq. (1), involving the term of general base catalysis, the plot of $k_{\mathrm{obsd}}-k_{\mathrm{o}} /[\mathrm{X}-\mathrm{BnA}]$ vs [X-BnA], Eq. (2), should be linear, and the expected linear plot was obtained as seen in Figure 2.

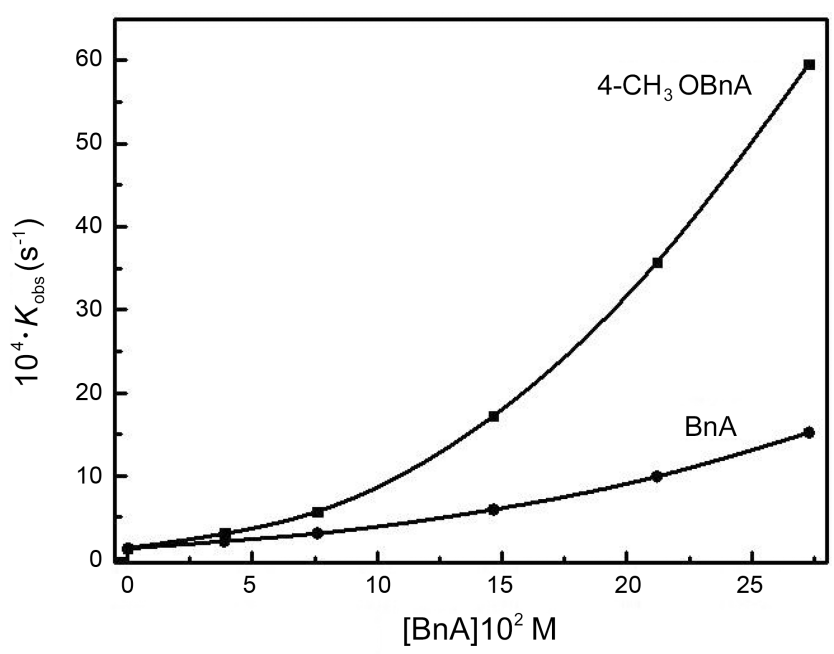

Figure 1. Plots of $k_{\text {obsd }}$ against amine concentrations for the reactions of 4-nitrobenzenesulfenyl chloride with benzylamine $(\bullet)$ and 4-methoxybenzylamine ( $\mathbf{a})$ in DMSO at $25^{\circ} \mathrm{C}$. 


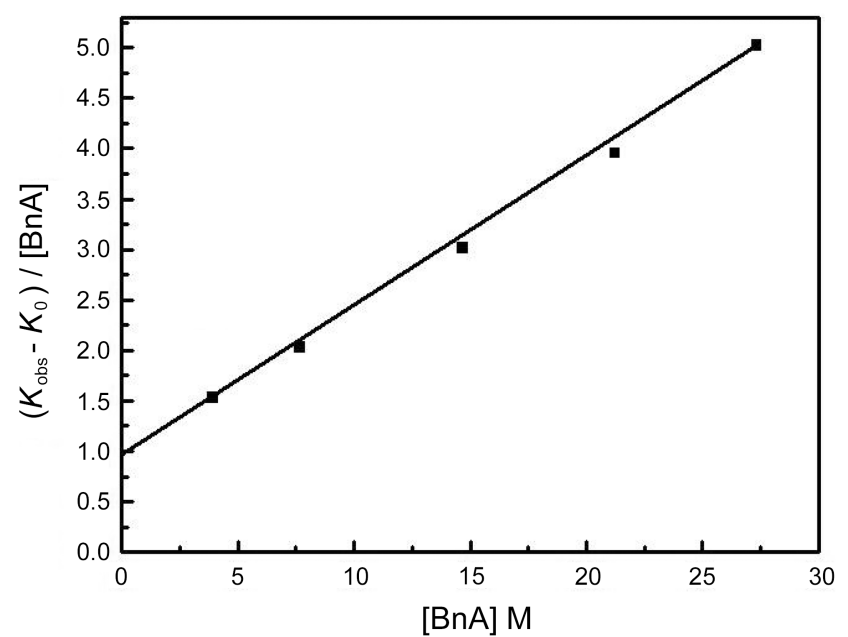

Figure 2. Plot of $\left(k_{\mathrm{obsd}}-k_{\mathrm{o}}\right) /[\mathrm{BnA}] v s[\mathrm{BnA}]$ for the reaction of 4nitrobenzenesulfenyl chloride with benzylamine in DMSO at $25^{\circ} \mathrm{C}$.

Table 2. Second and Third Order Rate Constants, $k_{2}\left(\times 10^{4} \mathrm{dm}^{3}\right.$ $\left.\mathrm{mol}^{-1} \mathrm{~s}^{-1}\right), k_{3}\left(\times 10^{2} \mathrm{dm}^{6} \mathrm{~mol}^{-2} \mathrm{~s}^{-1}\right)$ for the Reaction of 4-Nitrobenzenesulfenyl Chloride with X-Benzylamines in DMSO at $25^{\circ} \mathrm{C}$

\begin{tabular}{ccc}
\hline $\mathrm{X}$ & $10^{4} k_{2}$ & $10^{2} k_{3}$ \\
\hline $4-\mathrm{OCH}_{3}$ & 1.05 & $8.51(\mathrm{r}=0.9993)$ \\
\hline & $1.66(1.14)^{a}$ & $3.84(\mathrm{r}=0.9995)$ \\
$4-\mathrm{CH}_{3}$ & $k_{\mathrm{H}} / k_{\mathrm{D}}=1.45$ & $\begin{array}{c}1.60(\mathrm{r}=0.9897) \\
k_{\mathrm{H}} / k_{\mathrm{D}}=2.40\end{array}$ \\
\hline $\mathrm{H}$ & 3.73 & $1.68(\mathrm{r}=0.9994)$ \\
\hline & $0.115(0.088)^{a}$ & $0.396(\mathrm{r}=0.9997)$ \\
$4-\mathrm{Cl}$ & $k_{\mathrm{H}} / k_{\mathrm{D}}=1.30$ & $0.182(\mathrm{r}=0.9982)$ \\
& $2.10(\mathrm{r}=0.999)$ & $2.49(\mathrm{r}=0.999)$ \\
\hline$\beta_{\mathrm{x}}$ & $-2.08(\mathrm{r}=0.997)$ & $-2.59(\mathrm{r}=0.997)$ \\
\hline$\rho_{\mathrm{x}}$ &
\end{tabular}

${ }^{a}$ For deuterated X-benzylamine.

$$
\begin{aligned}
& k_{\mathrm{obs}}=k_{\mathrm{o}}+k_{2}[\mathrm{X}-\mathrm{BnA}]+k_{3}[\mathrm{X}-\mathrm{BnA}]^{2} \\
& \left(k_{\mathrm{obs}}-k_{\mathrm{o}}\right) /[\mathrm{X}-\mathrm{BnA}]=k_{2}+k_{3}[\mathrm{X}-\mathrm{BnA}]
\end{aligned}
$$

The $k_{0}, k_{2}$ and $k_{3}$ values obtained as the intercept $\left(k_{2}\right)$ and the slope $\left(k_{3}\right)$ of the plot are summerized in Table 2, together with the selectivity parameters, Bronsted coefficient $\beta_{\mathrm{x}}$ (Fig. 3) and Hammett constant $\rho_{\mathrm{x}}$ (Fig. 4).

In the present work, considerably large magnitudes of $\beta_{\mathrm{x}}$ and $\rho_{\mathrm{x}}$ values for both bimolecular $\left(k_{2}\right)$ and termolecular $\left(k_{3}\right)$ reactions strongly suggest a stepwise mechanism with a ratelimiting leaving group departure from the intermediate. ${ }^{8}$

As seen in Table 2, the catalytic rate constants $k_{3}$ are greater than those of uncatalytic rate constant $k_{2}$. Similar results were reported for the reaction of 4-chlorophenyl acetates with pyrrolidine and of phenylphenoxy acetate with benzylamines in $\mathrm{CH}_{3} \mathrm{CN}$. ${ }^{8,9}$ For the aminolysis of 4-nitrophenylacetate and triphenylmethylsulfenyl chloride ${ }^{10}$ the $k_{3}$ term was not observed, but both $k_{2}$ and $k_{3}$ terms were observed for chloro- and dichloroacetates in $\mathrm{CH}_{3} \mathrm{CN} .{ }^{11}$ These results indicate that a strong electron acceptor in aryl moiety requires general base catalysis in aprotic solvent.

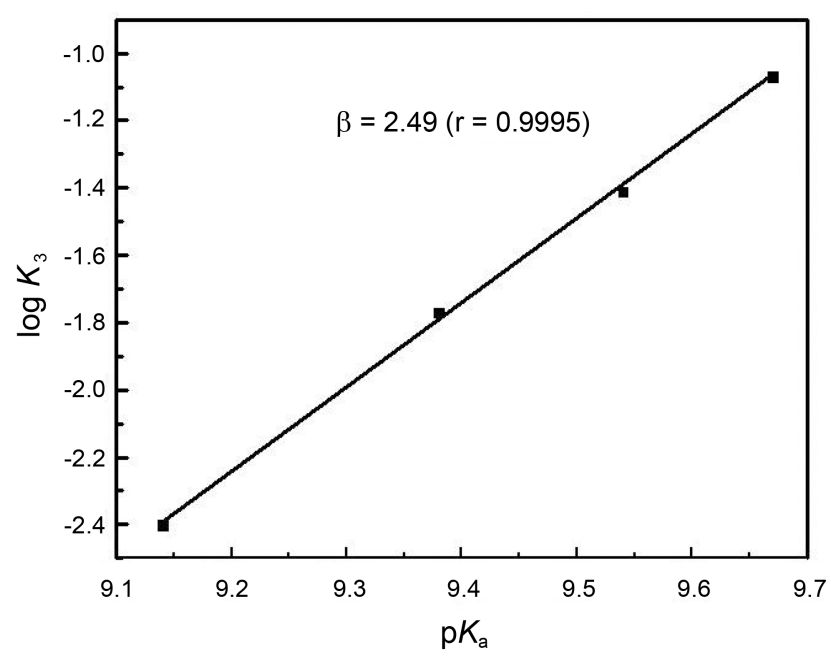

Figure 3. Bronsted plot for $k_{3}$ of the reactions of 4-nitrobenzenesulfenyl chloride with X-benzylamine in DMSO at $25^{\circ} \mathrm{C}$.

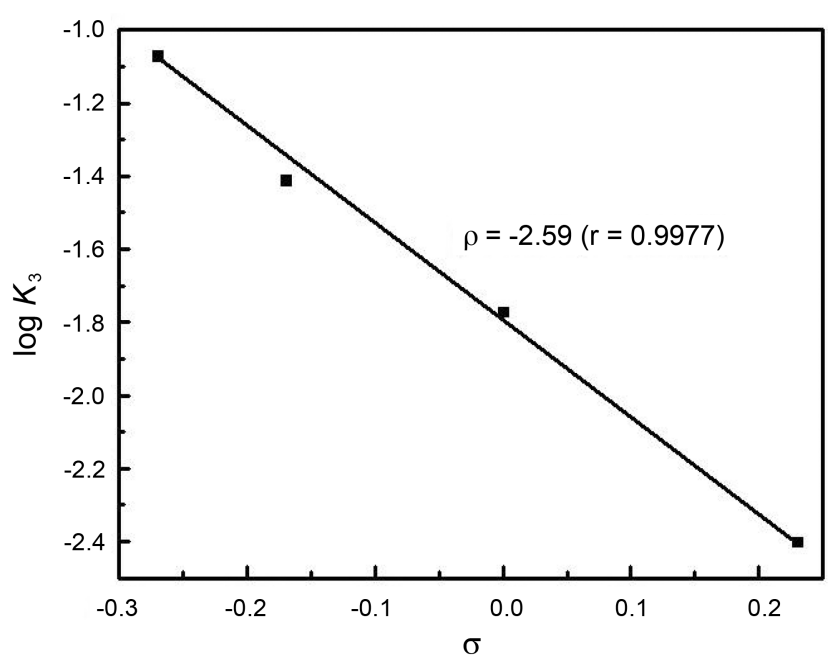

Figure 4. Hammett plot for $k_{3}$ of the reactions of 4-nitrobenzenesulfenyl chloride with X-benzylamine in DMSO at $25^{\circ} \mathrm{C}$.

Therefore, the $k_{3}$ term observed in this work might be attributed to the effect on a strong electron-withdrawing group $\left(4-\mathrm{NO}_{2}\right)$ in the substrate.

At a glance, the $\beta_{\mathrm{x}}$ value seems to be less reliable since the $\mathrm{p} K_{\mathrm{a}}$ values in water are used in the correlation instead of those in DMSO. However, $\Delta \mathrm{p} K_{\mathrm{a}}\left(=\mathrm{p} K_{\mathrm{DMSO}}-\mathrm{p} K_{\mathrm{H}_{2} \mathrm{O}}\right)$ are remained constant for various conjugate acids of amines so that the solvent effect on the value of $\beta_{\mathrm{x}}$ is not significant.

The $\beta_{\mathrm{x}}$ and $\rho_{\mathrm{x}}$ values for the catalyzed path, $k_{3}$, are larger than those for the uncatalyzed path, $k_{2}$.

To get more information on the TS structure for the catalyzed path, the deuterium kinetic isotope effects $\left(k_{\mathrm{H}} / k_{\mathrm{D}}\right)$ on two kinds of $\mathrm{X}$-benzylamines $\left(\mathrm{X}=4-\mathrm{CH}_{3}, 4-\mathrm{Cl}\right)$ are investigated. The values of $k_{\mathrm{H}} / k_{\mathrm{D}}(2.17-2.40)$ for the catalyzed path are much greater than those for uncatalyzed path $\left(k_{\mathrm{H}} / k_{\mathrm{D}}=1.30 \sim 1.45\right)$ as seen in Table 2 . The primary normal deuterium kinetic isotope effects $\left(k_{\mathrm{H}} / k_{\mathrm{D}}>1.0\right)$ provide the evidence of partial N-H(D) bond breaking in the TS. Thus, the authors suggest that the bimoleular uncatalyzed path 


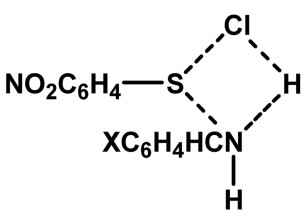

TS I

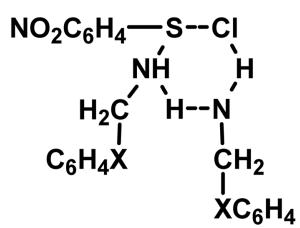

TS II
Scheme 2

proceeds through hydrogen bonded, four-center-type TS I while the termolecular catalyzed path proceeds through TS II involving six-membered ring with two benzylamine nucleophiles in Scheme 2.

In the $k_{3}$ path, relatively greater stretching of the $\mathrm{N}-\mathrm{H}$ bond is required than in the $k_{2}$ path, so the $k_{\mathrm{H}} / k_{\mathrm{D}}$ values are greater. This is consistent with larger degree of bond formation in the catalyzed path, as indicated by the larger magnitude of the $\beta_{\mathrm{x}}$ and $\rho_{\mathrm{x}}$ values.

This result is very unique in comparison with the smaller magnitudes of $\beta_{\mathrm{x}}(0.8-1.0)$ and $\rho_{\mathrm{x}}(-0.3 \sim-0.4)$ values for the pyridinolysis of tetracorrdinated sulfur compound, benzenesulfonyl chloride. ${ }^{12}$

\section{Summary}

The reactions of 4-nitrobenzenesulfenyl chloride with substituted benzylamines proceed through three pathways, the uncatalyzed $\left(k_{2}\right)$ and catalyzed $\left(k_{3}\right)$ paths including solvolysis $\left(k_{\mathrm{o}}\right)$ by the solvent. The large value of primary normal kinetic isotope effects imply that the proton transfer occurs concurrently from benzylamine to $\mathrm{Cl}$ atom of the substrate.

The $\beta_{\mathrm{x}}$ and $\rho_{\mathrm{x}}$ values for the catalyzed path, $k_{3}$, are greater than those for the uncatalyzed path, indicating that greater degree of bond formation in the catalyzed TS compared to the uncatalyzed TS.

\section{Experimental}

Materials. 4-Nitrobenzenesulfenyl chloride used as a substrate was purchased from Aldrich without further purification. Benzylamines, Aldrich and DMSO, Merck were of the best grade commercially avaliable and were generally recrystallized or distilled before use.

Kinetic Measurements. The rates for aminolysis were measured spectrophotometrically in DMSO at $25 \pm 0.1{ }^{\circ} \mathrm{C}$ by following the decrease in absorbance due to disappearance of the substrate at wavelengths in the range of 320-332 $\mathrm{nm}$. The rate measurements were carried out using a Hewlett Packard 8452 Diode Array spectrophotometer equipped with a Shimadzu TB-85-thermo bath to keep the temperature of the reaction mixture at $25 \pm 0.1{ }^{\circ} \mathrm{C}$. The reaction was carried out under pseudo first order condition in which the amine concentration was at least 10 times greater than that of the substrate. Typically, kinetic run was initiated by injecting $30 \mu \mathrm{L}$ of $1.0 \times 10^{-2} \mathrm{M}$ stock solution of the substrate in DMSO into $3.0 \mathrm{~mL}$ of amine solution maintained at $25 \pm 0.1$ ${ }^{\circ} \mathrm{C}$ in a cell compartment of the spectrophotometer.

Product Analysis. 4-Nitrobenzenesulfenyl Chloride was reacted with excess amount of benzylamine for more than 15 half-lives in DMSO at $25{ }^{\circ} \mathrm{C}$. The products were isolated by evaporating the solvent under reduced pressure after filtration. The crude product was chromatographed on a silica gel column with dichloromethane as an eluent. The analytical data are as follows.

$\mathrm{NO}_{2} \mathbf{C}_{6} \mathbf{H}_{4} \mathbf{S N H C H}_{2} \mathbf{C}_{6} \mathrm{H}_{5}$ : Colorless solid; $\mathrm{mp}$ 82-83.5 ${ }^{\circ} \mathrm{C}$; ${ }^{1} \mathrm{H}$ NMR $\left(200 \mathrm{MHz}, \mathrm{CDCl}_{3}\right) \delta 8.18(\mathrm{~d}, J=8.9 \mathrm{~Hz}, 2 \mathrm{H})$, 7.37-7.29 (m, 7H), $4.12(\mathrm{~d}, J=5.8 \mathrm{~Hz}, 2 \mathrm{H}), 3.11(\mathrm{t}, J=5.8$ $\mathrm{Hz}, 1 \mathrm{H}) ;{ }^{13} \mathrm{C}$ NMR $\left(50 \mathrm{MHz}, \mathrm{CDCl}_{3}\right) \delta 147.3,146.1,139.0$, 127.8, 126.7, 125.8, 124.0, 121.6, 56.4; Mass $(\mathrm{m} / \mathrm{z}) 260\left(\mathrm{M}^{+}\right)$.

Acknowledgments. This study was supported by the Dong-A University research fund.

\section{References}

1. Kice, J. L. Adv. Phys. Org. Chem. 1980, 17, 115.

2. Okuyama, T. The Chemistry of Sulphenic Acids and Their Derivatives; Wiley: Chichester, 1990; Chapter 18.

3. Okuyama, T.; Nagase, S. J. Chem Soc., Perkin Trans. 2 1994, 1011.

4. Lee, J. P.; Kim, W. R.; Okuyama, T. Bull. Korean Chem. Soc. 2009, 30, 493.

5. Lee, J. P.; Lee, H. W.; Okuyama, T.; Koo, I. S. Bull. Korean Chem. Soc. 2009, 30, 1893.

6. (a) Castro, E. A.; Pizzaro, M. I.; Santos, J. G. J. Org. Chem. 1996, 61, 5982. (b) Castro, E. A.; Ibanez, F.; Santos, J. G.; Ureta, C. J. Org. Chem. 1993, 58, 4908. (c) Castro, E. A.; Cubillos, M.; Santos, J. G. J. Org. Chem. 1996, 61, 3501. (d) Castro, E. A.; Araneda, C. A. J. Org. Chem. 1997, 62, 126.

7. Williams, A. Chem. Soc. Rev. 1994, 23, 93.

8. Koh, H. J.; Kim, T. H.; Lee, B. S.; Lee, I. J. Chem. Res.(S) 1996, 482; J. Chem. Res.(M) 1996, 2714.

9. Menger, F. M.; Smith, J. J. J. Am. Chem. Soc. 1972, 94, 384.

10. Ciuffarin, E.; Guaraldi, G. J. Am. Chem. Soc. 1969, 91, 1745.

11. Neuvonen, H. J. Chem. Soc. Perkin Trans. 2 1995, 951.

12. Hong, S. W.; Koh, H. J.; Lee, I. J. Phy. Org. Chem. 1999, 12, 425. 